precision engineering. To give two examples, it is necessary to know the lengths of the highest grade block gauges accurately to one part per million, and the permissible error on accurate yard scales is 0.0001 inch. Though the National Physical Laboratory, by using the metre and wave-lengths of light and by adopting the 1922 value of the imperial standard yard in relation to the metre, has been able to stabilize its basis of reference for length measurements in terms of the yard and its common submultiples for science and technology, unification of the yard standard for these purposes in the British Commonwealth and the United States can no longer be delayed.

With regard to the pound, the values currently in use when expressed in terms of the kilogram are : 1 imperial standard pound $=0.453592338 \mathrm{kgm}$.; 1 Canadian pound $=0.45359243 \mathrm{kgm}$. ; I United States pound $=0.4535924277 \mathrm{kgm}$.

There is evidenee that the imperial standard pound has diminished by about 7 parts in 10 millions since
1846. It is about 2 parts in 10 millions $(0.0014$ grain $)$ smaller than the United States and Canadian pounds, which are defined in terms of the very closely safeguarded international prototype kilogram. Though the discrepancy between the pounds is not at present causing any technical difficulty, the co-existence of independently defined pounds is unsatisfactory in science and technology.

The agreed international values of the yard and the pound fall between the existing United States and British units, and the international yard, which is the same as the Canadian yard, accords exactly with the relationship 1 inch $=25.4 \mathrm{~mm}$., which is already extensively used in Great Britain and abroad for approximate conversions. The adoption of the international values of the yard and the pound will be of particular benefit to all those concerned with accurate measurements of length and mass for scientific and technological purposes in the British Commonwealth and the United States.

\title{
OBITUARIES
}

\section{Dr. John Jackson, C.B.E., F.R.S.}

DR. JoHN JACKson died in Epsom Hospital on December 9 at the age of seventy-one. His interest in astronomy was aroused when he studied under Prof. Ludwig Becker at the University of Glasgow. There he received a thorough grounding in celestial mochanies and in spherical astronomy. From Glasgow he proceeded to Trinity College, Cambridge, and. was placed among the Wranglers as a result of the Mathematical Tripos Examination in 1912 and was awarded the Tyson Medal and Sheepshanks Exhibition. In 1914 he received the first Smith's Prize.

His attention was directed to the problem of retrograde satellite orbits and, in particular, to the motion of Jupiter's eighth satellite. This satellite had been discovered by Melotte at the Royal Observatory, Greenwich, in 1908. It was the first satellite of Jupiter with a retrograde motion to be discovered and, because of the perturbing action of the Sun, its movement is very complicated. Observations of this satellite are difficult to obtain and are few in number, so that its orbit is even now rather uncertain. In 1914 Jackson was awarded the Mackinnon Studentship of the Royal Society for research on the motion of this satellite, but shortly afterwards he was appointed chief assistant at the Royal Observatory, Greenwich. He remained there for nineteen years and, during that time, he entered fully into all the programmes of observation that were undertaken.

His first important work at Greenwich was concerned with the observations of binary stars that had been made there with the 28 -in. refractor over a period of many years. These observations had been published in the annual volumes of Greenwich Observations, but no use had been made of them. He determined the orbits of a number of these binary systems, and combined the observations made at Greenwich with those that had been made elsewhere. For many of the systems, the periods of which were long, observations have not been extended over sufficient years for orbits to be derived; but the observations of these systems were used to infer their parallaxes and Jackson derived the hypothetical parallaxes of 556 systems.

In 1924 the Shortt free-pendulum clocks were introduced at the Observatory as the standards of time, replacing the regulator clocks that had previously been used. Jackson, in conjunction with W. Bowyer, discussed their performance and showed that, as a result of the nutation of the Earth's axis, sidereal time was not uniform. As a result of these investigations, astronomers have since had to distinguish between apparent and mean sidereal time. Jackson looked into the possibility that the accurate time-keeping of these clocks might provide information about the variability in the rotation of the Earth, but concluded that they were not sufficiently accurate to give trustworthy determination of the variability.

Another important piece of work, undertaken in collaboration with Dr. H. Knox-Shaw, the Radeliffe Observer at Oxford, and his assistant, Mr. Robinson, was a careful reduction of the observations of the Sun, Moon, planets and stars, which had been made at the Radcliffe Observatory, Oxford, during the years 1774-98 by Hornsby. These observations had not been reduced and, for their epoch, were of high accuracy. Such early positions of these bodies are of value in connexion with the determination of the proper motions of the stars, and the investigation of the orbits of the Sun, Moon and planets.

In 1933 Jackson was appointed H.M. Astronomer Royal at the Royal Observatory, Cape of Good Hope, and held that position until his retirement in 1950 , when he returned to Great Britain to take up residence. The Cape Observatory has a long tradition of accurate meridian and astrometric observations. The principal programmes of observation undertaken during Jackson's tenure of office were fundamental meridian observations with the Gill transit circle, the determination of positions and proper motions of stars, the determination of parallaxes of southern stars and the preparation of a photographic catalogue of southern stars between $30^{\circ} \mathrm{S}$. and the South Pole. 
Under his direction, Dr. R. H. Stoy, who, on Dr. Jackson's retirement, succeeded him as H.M. Astronomer, undertook the determination of the magnitudes of the brighter southern stars, which has established the photometry of the southern stars on a satisfactory and accurate basis.

During the Second World War the staff at the Observatory was much reduced, many members having left to undertake war-work of various sorts. Nevertheless, the output of observations continued at a remarkably high rate, Dr. Jackson himself being an assiduous observer.

Among his other interests was the observation of total eclipses of the Sun. While at Greenwich he obtained successful observations of the total eclipse of 1927 at Giggleswick and that of 1932 at Parent in Canada. He had also led an eclipse expedition to Alor Star, Kedah, Malaya, in 1929, when clouds unfortunately prevented observations being obtained. In 1940, when the War prevented the eclipse expedition from Greenwich proceeding to South Africa for the observation of the total solar eclipse in that year, the instrumental equipment was sent to South Africa, and under Jackson's direction the eclipse was observed under clear conditions at Calvinia in Cape Province.

Dr. Jackson was elected a Fellow of the Royal Astronomical Society in 1913 and served as secretary during 1924-29. After his return to Britain he was elected president of the Society for the period 195355. He was elected a Fellow of the Royal Society in 1938. He was president of the Commission on Meridian Astronomy of the International Astronomical Union during 1935-38, and president of the Commission on Parallaxes and Proper Motions during 1938-52. In 1952 he was awarded the Gold Medal of the Royal Astronomical Society for his work on stellar parallaxes and his contributions to the general problems of star positions and proper motions. Last year he was awarded the Gill Medal of the Astronomical Society of South Africa for his important contributions to astronomy during his period as H.M. Astronomer. He was made C.B.E. in 1950.

\section{H. SPENCER Jones}

\section{Sir James Myers, O.B.E.}

Sir James Myers, whose death was reported recently, had been associated with Manchester throughout his academic life. $\mathrm{He}$ was graduate in chemistry of Manchester, he served for a period as senior lecturer in chemistry and as secretary and tutor of the Faculty of Science of the University, and then, after a period as principal of the Manchester College of Technology, he was director of the School of Education of the University of Manchester.

Sir James was principal of the Manchester College of Technology during 1938-51-a period of very obvious difficulty. He had been a prominent member of the Faculty of Science in the University of Manchester, and it was hoped that he would consolidate relationships between the College as the Faculty of Technology and the rest of the University; instead, he was thrust into the hurly-burly of adaptation to the war effort. Under his guidance the College performed sterling work in both the educational and industrial fields.

There is little doubt, however, that he was not in his element in this sort of capacity; he preferred a slower-moving philosophical life. This was not to be, however. When the War ended, the College was one of the first university institutions to proceed with extensions, and the trials and tribulations of this activity again fell largely on his shoulders. It was not surprising that, in 1951, after receiving a knighthood for his services to technological education, he withdrew to the more peaceful pastures of the School of Education in Manchester.

I had the privilege of working under him for six years. He was a delightful person to know-full of warm humanity, of witty stories told with a strain of philosophy that left its mark, of wise advice to his subordinates. He was a gentleman in every sense of the word, and his influence on the College will be felt for a long time.

H. LIPSON

\section{Dr. Kenneth W. Neatby}

Dr. Kenneth W. Neatby, director of Science Service in the Canada Department of Agriculture, died on October 27. His death will be a very distinct loss to agricultural science and particularly to his own Service, which he has been directing for the past twelve years, and in which he was successful in building an effective research atmosphere. During the spring and surnmer of 1958, he had been instructed to take the lead in the formation of a Research Branch in the Canada Department of Agriculture through the amalgamation of Science Service and the Experimental Farms Service.

Dr. Neatby's career in research began with his appointment, in 1926, to the staff of the Dominion Rust Research Laboratory in Winnipeg. In addition to the actual development of varieties of wheat that were resistant to stem and leaf rust, he began a series of intensive studies of the inheritance of resistance to rust in wheat. Out of his work there came a much clearer understanding of the relation between the genes for resistance to rust and the various physiological races of the rust organism. This formed the foundation for work that is still going on and becoming increasingly valuable in our understanding of the cereal rust problem.

In 1935 , Dr. Neatby went to the University of Alberta in Edmonton as head of the Department of Field Crops. This was perhaps the beginning of his intense interest in education, particularly for a research career in biology. His writings and addresses on this subject have undoubtedly had an important influence on the course of agricultural education and research in Canada. Some excerpts from an address given at Macdonald College are examples of his thinking: "The student who allows the laboratory to keep him from the library, thereby depriving himself of the influence of great men of the past in other fields of learning, as well as his own, may become a competent technician but he is unlikely to become an influential scientist." "We hear a lot about training for research, but surely this is either a contradiction in terms or a misapplication. Fruitful research depends on knowledge, imagination, ideas and dogged perseverance, not on techniques derived by formal training, essential as these may be."

During 1940-46, Dr. Neatby was director of the Farm Service of the North-West Line Elevators Association at Winnipeg. Here, he gained a firsthand knowledge of agxicultural problems and became very conscious of the need for first-class research work in agriculture. From 1946 on, as director of Science Service, he built up an organization which has become very well known for its contributions in biology. C. H. Goulden 